\title{
AZOILDA LORETTA DA TRINDADE E O LEGADO DO PROJETO A COR DA CULTURA
}

AZOILDA LORETTO DA TRINDADE AND THE LEGACY OF THE CULTURE COLOR PROJECT

\author{
https://orcid.org/0000-0002-3041-6184 Gisele Rose da Silva ${ }^{\mathrm{A}}$ \\ ${ }^{\text {A }}$ Secretaria Estadual de Educação do Rio de Janeiro (Seeduc RJ), Rio de Janeiro, RJ, Brasil
}

Recebido em: 29 abr. 2021 | Aceito em: 30 ago. 2021

Correspondência: Gisele Rose GRS (rose.gisele@gmail.com)

\begin{abstract}
Resumo
No ano de 2003, a Lei 10.639 estabeleceu a obrigatoriedade do ensino de conteúdos de História da África e dos negros no Brasil em todo currículo escolar brasileiro, e com base na referida lei, no ano de 2004, o Canal Futura em parceria com a Petrobras, o Cidan - Centro de Informação e Documentação do Artista Negro, o MEC - Ministério da Educação e Cultura, a Fundação Palmares, a TV Globo e a Seppir - Secretaria de Políticas de Promoção da Igualdade Racial iniciaram o projeto educativo "A Cor da Cultura". Idealizado pela intelectual negra Azoillda Loretto da Trindade, o projeto foi difundido em todo país, produzindo materiais audiovisuais, ações culturais e educativas, visando práticas positivas e de reconhecimento e preservação das culturas afro-brasileiras.
\end{abstract}

Palavras-chave: Lei 10.639/03; a cor da Cultura; Azoilda Loretto da Trindade.

\begin{abstract}
In the year 2003, Law 10.639 established the mandatory teaching of African and African History contents in Brazil in all Brazilian school curricula, and based on that law, in 2004, Canal Futura in partnership with Petrobras, Cidan - Black Artist Information and Documentation Center, MEC - Ministry of Education and Culture, Fundação Palmares, TV Globo and Seppir - Secretariat for Policies to Promote Racial Equality started the educational project "A Cor of culture". Conceived by the black intellectual Azoillda Loretto da Trindade, the project was disseminated throughout the country, producing audiovisual materials, cultural and educational actions, aiming at positive practices and for the recognition and preservation of Afro-Brazilian cultures.
\end{abstract}

Keywords: Law 10.639/03; the color of Culture; Azoilda Loretto da Trindade. 


\section{Introdução}

O marco histórico da Lei 10.639/03 evidencia uma demanda de formação e qualificação de docentes e instituições de ensino, ressaltando a necessidade de construção de curso de formação para fomentar a renovação de currículos e práticas, diante desta realidade surgiu a necessidade de se pensar:

Um projeto que incluiu em seus materiais educativos audiovisuais e impressos um pouco da história das vivências e da riqueza cultural do negro, recuperando temas e promovendo discussões que deveriam fazer parte do dia a dia da sociedade (BRANDÃO e SANTOS, 2015) e agregou educadores e ativistas de suma importância nas discussões étnico-raciais em nosso país para colaborarem com textos e vivências e capacitar tantos outros educadores e educadoras no Brasil.

O projeto A cor da Cultura teve como ideia criar um espaço de discussão entre alunos, alunas, educadores e educadoras sobre as questões ligadas à participação social dos descendentes africanos (BRANDÃO e SANTOS, 2015), valorizando as formas de expressão do negro, atendendo assim, os propósitos da Lei 10.639/03 (SILVA, 2020:36-37).

No processo de formação de educadores e educadoras, se torna imprescindível uma reorganização de termos de conhecimentos pedagógicos, qual seja uma reeducação para as relações ético-raciais, que traz a necessidade de rever conteúdos que foram marcados pelo eurocentrismo. Dito isto, o programa "A Cor da Cultura" prevê uma série de atividades com o objetivo de tornar acessíveis às escolas os conteúdos dos programas, visando implementar ações culturais e educativas de forma a contribuir para a valorização e preservação da culturas afrobrasileiras, ressaltando a diversidade, pois:

Num mundo de grandes desigualdades, nem sempre é fácil lidar com a diferença. Ela está em toda parte. Por vezes, é mais simples percebê-la quando a questão envolve apenas dois times de futebol, duas religiões, dois partidos políticos, duas formas de agir. $\mathrm{Na}$ abordagem de temas mais complexos, ou simplesmente se a proposta exige um exercício crítico rigoroso, podemos dizer que, mesmo entre os mais semelhantes, habitam numerosas diferenças - afinal, cada ser humano é único no conjunto de suas características. (BRANDÃO e SANTOS, 2015b: 9).

Como coordenadora pedagógica do projeto A Cor da Cultura, Azoilda Loretto da Trindade contribuiu para divulgar ações e iniciativas de educadores, escolas e organizações não governamentais no âmbito das relações raciais e educação, dando prioridade às metodologias pedagógicas para aplicação das diretrizes curriculares para a educação das relações étnicoraciais. É imprescindível ressaltar que o programa A Cor da Cultura foi a grande referência para a formação de professores, dando conta da Lei 10.639, e foi o único projeto nacional que tratava 
de questões étnico-raciais e que é lembrado por todas e todos que tiveram o prazer de participar, pois foram formados articuladores que atuam ainda hoje em todo país (SILVA, 2020).

\section{Azoilda Loretto da Trindade}

Rememorar a importância da intelectual negra Azoilda Loretto da Trindade para a discussão das relações étnico-raciais no Brasil é destacar o processo de valorização da nossa afro-brasilidade e resgatando a África que existe dentro de cada um de nós, e mostrado que todo e qualquer espaço que pode e deve ser ocupado para pensar as questões de diversidade.

Como educadora, Azoilda teve sua vida voltada para pensar teorias e práticas que contribuíssem para um cotidiano escolar que abraçasse todas as singularidades, dentro da perspectiva de uma educação antirracista, como intelectual elaborou projetos, textos e livros e como militante teve uma vida repleta de atuações de suma importância para a história do movimento negro.

Como descreveu Azoilda Loretto, nessa trajetória de pesquisa e militância antirracista, percebemos a existência de uma polaridade muito grande quando se discute e se aborda a questão racial. Com relação ao binômio racismo-educação, essa polaridade se repete: não encontramos, a nível de livros e/ou artigos, qualquer texto que aborde a questão do racismo na escola e que não tenda para brancos x negros, brancos x índios (TRINDADE, 1994).

Com base na trajetória da intelectual negra Azoilda Loretto da Trindade, podemos afirmar que:

Azoilda é o próprio baobá, essa árvore nativa da África que pertence à família das malváceas, parente dos hibiscos e da malva, com seu tronco, em forma de cone, pode chegar a 09 metros de diâmetro e a 30 metros de altura, que ela adorava, pois ela deixou sementes em diversos lugares, (informação verbal de Janete Ribeiro, APÊNDICE E), e que este símbolo se perpetue e nos proporcione reverências, memórias, ancestralidade e axé (SILVA, 2020:23).

\section{O programa a cor da cultura}

A Fundação Roberto Marinho/Canal Futura criou o programa "A Cor da Cultura" em 2004. Baseado nos princípios de equidade, respeito às diferenças, pluralidade, diversidade, diálogo e trocas, o projeto tem como objetivo contribuir para a valorização do patrimônio cultural afro-brasileiro. Como parte do projeto, foram realizadas pesquisas e produzidos diversos recursos didático-pedagógicos visando incluir a temática nas agendas das escolas 
através da formação de educadores e educadoras (professores de vários níveis, coordenadores pedagógicos, técnicos das secretarias de educação, graduandos e representantes do movimento social) e da doação dos kits pedagógicos às escolas, universidades e ONGs que trabalhavam com a temática racial.

O projeto "A Cor da Cultura" tem início no ano de 2004 e, enquanto projeto social com o objetivo de valorizar o patrimônio cultural afro-brasileiro e reconhecer a contribuição da população negra à sociedade brasileira dando visibilidade a sua história não associada à escravidão. De forma inédita e inovadora instituições públicas e privadas se reuniam para desenvolver um conjunto de produtos destinados à ação pedagógica, em escolas públicas, relativa à implementação da lei 9394/1996, de Diretrizes e Bases da Educação Nacional (LDB) alterada pela lei 10.639/2003. Foi uma parceria entre o Canal Futura, o Cidan - Centro de Informação e Documentação do Artista Negro, a Seppir - Secretaria Especial de Políticas de Promoção da Igualdade Racial, a TV Globo, a TV Educativa e a Petrobras, visando unir esforços para a valorização e preservação do patrimônio cultural afro-brasileiro. ${ }^{i}$

O Programa A Cor da Cultura fez parte do plano nacional de implementação da Lei 10.639/2003, pois em dezembro de 2007 o Ministério da Educação em resposta às proposições encaminhadas pelos participantes de um Workshop sobre a implementação da Lei 10.639/2003, realizado em parceria pelo MEC/SECAD e a representação da UNESCO no Brasil instituiu um Grupo de Trabalho para elaborar um Plano Nacional de Implementação das Diretrizes Curriculares para a Educação das Relações Étnico Raciais. Este grupo foi coordenado pela Secretaria de Educação Continuada, Alfabetização e Diversidade e as Secretarias de Educação Básica, de Educação Técnica, de Ensino Superior e Instituto Nacional de Estudos e Pesquisas Educacionais Anísio Teixeira (INEP) estão representadas por gestores (as) e/ou técnicos (as) os (as) quais sistematizaram e apresentaram as ações e programas desenvolvidos por essas secretarias após a publicação da Lei 10.639/2003.

Participam também deste grupo representantes das seguintes instituições: Associação Brasileira de Pesquisadores Negros (ABPN); Associação Nacional de Pesquisa em Educação (ANPed); Ação Educativa; Centro de Estudos das Relações do Trabalho e Desigualdades (Ceert); Centro do Estudante Afrobrasileiro (Ceafro); Canal Futura; Conselho Nacional de Educação (CNE); Conselho Nacional de Secretários Estaduais de Educação (CONSED); Secretaria Especial de Políticas de Promoção da Igualdade Racial (SEPPIR); Secretaria de Direitos Humanos (SEDH); União Nacional de Dirigentes Municipais de Educação (UNDIME); UNESCO e UNICEF ${ }^{\mathrm{ii}}$. 
O projeto "A Cor da Cultura" tem dois grandes componentes: a produção audiovisual e a formação de professores, no âmbito da produção audiovisual, o projeto inclui cinco grades de programação, que são os programas:

1) “Ação", exibido na TV Globo e na Canal Futura, que propôs a produção de quatro episódios dedicados a retratar iniciativas sociais afirmativas desenvolvidas por organizações não-governamentais em todo o país que tenham a população afrodescendente;

2) "Livros Animados", que teve dez edições e incentiva a leitura junto ao público infantil, destacando escritores, temáticas afro-brasileiras e africanas e visibilidade de artistas negros em várias áreas - da interpretação à produção literária.

3) O programa "Nota 10", do Canal Futura, voltado para metodologia de ensino e formação de educadores, que teve cinco edições com exibição de práticas pedagógicas, bem como a realização de debate com educadores sobre História e Cultura afro-brasileira;

4) "Heróis de todo mundo" uma série com trinta programas de dois minutos de duração cada, que retrata vida e a obra de homens e mulheres negros que se destacaram nas diferentes áreas do conhecimento no Brasil;

5) "Mojubá", exibido no Canal Futura e na TVE, com sete documentários sobre as religiosidades de matriz africana, a história dos quilombos e de outros valores da negritude presentes na cultura brasileira.

O projeto prevê uma série de ações culturais e educativas com foco na produção e veiculação de programas sobre o histórico de contribuição da população negra à sociedade brasileira. Esta produção, transformada em material didático, aplicado e distribuído nas escolas públicas, deverá ampliar o conhecimento e a compreensão sobre a história dos afrodescendentes e histórica da África e tem como objetivos: criar materiais audiovisuais sobre história e cultura afro-brasileiras; valorizar iniciativas de inclusão, dando visibilidade a ações afirmativas já promovidas pela sociedade e contribuir para a criação de práticas pedagógicas inclusivas e possui como marco inicial:

Reconhecer exige que se questionem relações étnico-raciais baseadas em preconceitos que desqualificam os negros e salientam estereótipos depreciativos, palavras e atitudes que, velada ou explicitamente violentas, expressam sentimentos de superioridade em relação aos negros, próprios de uma sociedade hierárquica e desigual. Reconhecer é também valorizar, divulgar e respeitar os processos históricos de resistência negra desencadeados pelos africanos escravizados no Brasil e por seus descendentes na contemporaneidade, desde as formas individuais até as coletivas. Reconhecer exige a valorização e respeito às pessoas negras, à sua descendência africana, sua cultura e história. Significa buscar, compreender seus valores e lutas, ser sensível ao sofrimento causado por tantas formas de desqualificação: apelidos depreciativos, brincadeiras, piadas de mau gosto sugerindo incapacidade, ridicularizando seus traços físicos, a textura de seus cabelos, fazendo pouco das religiões de raiz africana. Implica criar 
condições para que os estudantes negros não sejam rejeitados em virtude da cor da sua pele, menosprezados em virtude de seus antepassados terem sido explorados como escravos, não sejam desencorajados de prosseguir estudos, de estudar questões que dizem respeito à comunidade negra. Parecer elaborado pela Prof. Petronilha Beatriz Gonçalves e Silva, membro do Conselho Nacional de Educação para fundamentação das Diretrizes Curriculares Nacionais para a Educação das Relações Étnico-Raciais e para o Ensino de História e Cultura Afro-brasileira e Africana. (BRASIL, 2004:3-4)

O programa "A Cor da Cultura" iii tem como objetivo: 1) formar/capacitar os (as) professores (as) indicados(as) pelas secretarias municipais e estaduais de educação para implementação/utilização do material pedagógico "A Cor da Cultura", ampliando assim o conhecimento e a compreensão sobre a história dos(as) afrodescendentes e a história da África e contribuindo para que os objetivos previstos da referida Lei venham a ser atingidos; 2) fomentar a formação docente acerca das africanidades brasileiras; 3) planejar ações pedagógicas que estabeleçam uma estreita relação entre o material pedagógico "A Cor da Cultura" e o universo dos docentes, as suas realidades, no cotidiano diverso do universo escolar; 4) disseminar contribuições e participações da(s) cultura(s) negra(s) para a sociedade brasileira como um todo e contribuir, pelo caminho da ação educativa escolar, para a erradicação dos efeitos das discriminações sociais e étnico-raciais que perpassam o nosso país e:

O que propomos é que, ao assistirmos aos programas do projeto A cor da Cultura e nos depararmos com falas, práticas e credos distintos dos nossos, ou daqueles que desejamos ter, possamos ouvi-los, vê-los e senti-los profunda e respeitosamente. E mesmo que não mudemos o nosso modo de ser, saibamos que nossa leitura está sendo o tempo todo atravessada - ou, como dizem nos estudos de Educação, mediada - por um lugar no mundo que acreditamos ocupar. Abrirmos à nossa frente essas diferentes histórias pode nos ajudar a rever esse lugar (BRANDÃO e SANTOS, 2015a: 13).

Vale ressaltar que, quando a Lei 10.639/03 foi promulgada, surgiu a impressão de que, a princípio, esta obrigatoriedade recairia apenas sobre os docentes da Educação Básica e estes teriam que promover práticas que pudessem suprir as necessidades da discussão sobre a História da África e dos afrodescendentes no Brasil. Porém, posteriormente, foi comprovado que aplicação da referida lei se daria em todos os níveis de ensino.

De acordo com a avaliação do programa "A Cor da Cultura" , podemos destacar que: o programa atendeu, expressivamente, ao Ensino Fundamental (cerca de 70\%) e foi expandido para outras escolas (segundo 1/3 dos gestores), alunos (79\%) e professores $(85,3 \%$ ) se colocaram mais sensíveis quanto à necessidade de eliminação de práticas discriminatórias; a maioria dos professores das escolas priorizou a discussão dos temas propostos $(75,6 \%) \mathrm{e}$ tiveram facilidade para articulá-los aos conteúdos de suas áreas e disciplinas (59,5\%); o 
programa criou raízes em boa parte das escolas mediante a revisão de propostas curriculares, a discussão do projeto político pedagógico ou criação de grupos de estudo em torno dos temas.

Ainda que a Lei 10.639/03 represente uma importante conquista, é evidente que o texto da lei não representou, por si só, a promoção de uma pedagogia antirracista, visto que um dos desafios do programa foi o baixo investimento financeiro das Secretarias Municipais de Educação (SME), a fluidez ou inexistência de acompanhamento pelos órgãos municipais e a participação restrita de outros atores no planejamento das ações (universidades, ONGs e outros grupos culturais e religiosos etc.).

\section{Ações para uma educação antirracista}

O projeto “A Cor da Cultura” propõe uma educação antirracista, que significa, antes de qualquer coisa, compreender que o racismo existe e permeia as instituições de ensino no Brasil e isso ocorre porque na nossa estrutura social o racismo é uma constante e pode ser apresentado de várias formas, pois:

A realidade multicultural de nossa sociedade será sempre a justificativa para a defesa de uma educação antirracista que respeite as diferenças culturais. Azoilda ressaltava a necessidade de enfatizar que a palavra "diferença" não podia estar diretamente atrelada apenas aos portadores de necessidades especiais, mas deveria ser aplicada quando falamos das culturas negras e indígenas.

Dito isto, lutar para que a lei 10.639/03 seja devidamente implementada nas instituições de ensino e que seja propagada por todo corpo docente é uma das primeiras alternativas na busca de um espaço onde não prevaleça a unanimidade de um grupo (SIILVA, 2020: 44)

A questão é iniciada através de ideias que são reproduzidas corriqueiramente no ambiente escolar, como por exemplo, a de que os negros contribuíram para a formação do Brasil. Se analisarmos de forma mais ampla esta afirmativa, perceberemos que ela dá a entender que se o povo negro contribuiu, é porque já existia um Brasil completamente construído. Não é assim que analisaremos, posto que o povo negro participou efetivamente da formação do Brasil e também da formação do que chamamos de povo brasileiro.

No momento em que uma educadora ou educador se nega a discutir a diversidade racial que constitui a estrutura do nosso país, afirmando que somos todos iguais; que utiliza o imaginário do europeu colonizador; que parte de um padrão eurocêntrico e naturaliza a narrativa de uma única história, hierarquizando a produção cultura e de conhecimento dos grupos humanos não-europeus e tratando-os como primitivos, inferiores ou até mesmo irracionais, 
torna-se necessário criar um ambiente onde exista a desconstrução dessas ideias e a inserção de uma outra história.

Pensar uma educação antirracista significa propor uma ação pautada no reconhecimento da diferença e da luta contra todas formas de discriminação. Dito isto, precisamos, inclusive, compreender os tantos danos que o racismo causa no cotidiano escolar e repensar essa situação, pois:

\begin{abstract}
Acreditamos, como seres humanos comprometidos com a educação deste país, que mudanças metodológicas, didático-pedagógicas, de mentalidade e da práxis precisam com urgência ser implementadas. Cada vez mais se acirra o abismo entre a educação escolar (sobretudo a pública municipal e estadual), o trabalho, as práticas sociais e a experiência extraescolar. [...] Escolas quebradas, gradeadas, assaltadas, apedrejadas, pichadas, violadas, militarizadas, policiadas... (TRINDADE, 2011: 8)
\end{abstract}

Nesse sentindo, é fundamental entender que uma das principais formas de praticar uma educação antirracista é proporcionar sujeitos de diversas raças e etnias sejam representadas no cotidiano escolar nas mais variadas formas, valorizar a imagem e a importância da prática de uma educação que seja voltada para a diversidade, corrigindo práticas racistas que são apresentadas de forma estrutural em nosso cotidiano escolar.

\begin{abstract}
Pensar uma educação antirracista que torne visível de forma igualitária personalidades, pensadores, pesquisadores de todas as raças e etnias que formaram nosso país e que, ainda hoje, contribuem para a construção de uma educação que respeite todas as subjetividades de todos aqueles que estão inseridos no âmbito escolar é uma das metas primordiais e fundamentais para uma educação pautada na diversidade.

Atuar dentro da perspectiva de uma educação que seja de fato antirracista é perceber a diversidade das existências presentes no espaço escolar, é compreender cada ser como único e múltiplo e compreender cada anseio e possibilitar práticas que ressaltem afetos e humanidade (SILVA, 2020: 45).
\end{abstract}

Nos momentos de grande exclusão social, como os tempos atuais, é importante perceber que a educação antirracista precisa ressaltar as diversidades presentes nas existências dos sujeitos inseridos no cotidiano escolar, tendo este contexto como eixo que compreende que a estrutura racista permitiu que a História e Cultura Africana fossem invisibilizadas ao longo dos séculos, pois:

\footnotetext{
A ausência quase total de protagonistas negros influencia a forma de as pessoas verem a realidade. Quando se observa que o negro só aparece como coadjuvante ou com sua imagem vinculada a algo negativo, seja na novela da TV ou na matéria do jornal, compreende-se como a mídia pode influenciar a maneira de as pessoas entenderem as relações dos grupos étnicos na sociedade, perpetuando os preconceitos. A representação do negro ou a ausência dela -seguindo os padrões que o colocam em posições subalternas, faz com que grande parte da sociedade reproduza as "vozes do racismo" (BRANDÃO e SANTOS, 2015a: 13).
}

Revista Interinstitucional Artes de Educar. Rio de Janeiro, V.7, N.2 - pág. 805-820 mai-ago de 2021: "Dossiê História das Mulheres e Educação” - DOI: 10.12957/riae.2021.63430 
Uma educação antirracista se aplica dentro do cotidiano escolar com base na diversidade e na troca de saberes respeitando as subjetividades e singularidades presentes dentro do espaço escolar. Sendo assim, o que se busca é uma educação que respeite cada indivíduo. Isso significa propor uma prática a partir de valores civilizatórios afro-brasileiros, buscando uma nova estrutura educacional, com base na compreensão e no respeito às experiências desses alunos e alunas inseridos num sistema de invisibilidade que, dentro deste processo, emergem como sujeitos visíveis através de:

\begin{abstract}
Uma prática docente que seja voltada para a diversidade étnica e cultural da nossa população, sobretudo dessa população que ao longo da história do Brasil, vem sendo alijada dos direitos civis, sociais e humanos, dessa população que dorme nas filas por uma vaga na escola pública. Uma prática docente política ideológica e humanamente comprometida como nosso povo mestiço, belo, forte, que luta que surpreende, que ri, que chora, que cria cotidianamente saberes e estratégias, práticas que possibilite viver/sobreviver, num tempo em que a exclusão social é vista como um valor positivo e como inevitável (TRINDADE e SANTOS, 1999: 16).
\end{abstract}

Através de uma educação antirracista baseada principalmente no ideal de ressaltar a diversidade em prol do reconhecimento de subjetividades que historicamente foram invisibilizadas. Para tanto, é necessário propor uma prática docente diferenciada que possa abranger todo corpo discente. Ressaltar a diversidade é compreender que podemos e devemos ser múltiplos e diversos e que o cotidiano escolar deve ser acolhedor, maximizando o respeito e a coletividade.

\title{
Metodologia do programa a cor da cultura
}

O projeto "A Cor da Cultura" teve sua metodologia desenvolvida por Azoilda Loretto da Trindade, pedagoga e doutora em Comunicação pela Escola de Comunicação da Universidade Federal do Rio de Janeiro (UFRJ), intelectual negra e ativista de suma importância nos períodos que antecedem a promulgação da Lei 10.639/03 e durante sua implementação.

$\mathrm{Na}$ construção do percurso metodológico, percebemos a inserção dos valores civilizatórios afro-brasileiros como proposta propiciadora de possibilidades de narrar novas histórias, inserindo alunos e alunas, com suas subjetividades, dentro deste ambiente escolar que pode e deve ser acolhedor e respeitoso com todas e todos, pois:

Um dos caminhos propostos por Azoilda para uma educação antirracista dentro
e fora dos espaços escolares, seriam os valores civilizatórios afro-brasileiros 
que destacam a África, a sua diversidade, e o fato de que os africanos e africanas trazidos ou vindos para o Brasil e seus descendentes brasileiros, implantaram, marcaram e instituíram valores civilizatórios neste país (TRINDADE, 2005b) (SILVA, 2020, p. 47).

Os valores civilizatórios afro-brasileiros como proposta metodológica de ressignificação da cultura afro-brasileiras, são fundamentais para a construção de um projeto pedagógico pautado no antirracismo e podem ser pensados e aplicados dentro e fora das instituições de ensino, agindo como estratégia de múltiplas atuações, pois:

Ao pensarmos sobre os valores civilizatórios afro-brasileiros, criamos possibilidades de contar novas histórias, de inserir sujeitos e subjetividades, dentro deste ambiente escolar que pode, e deve ser acolhedor e respeitoso com todas e todos. Incentivar a construção de identidades é: dar visibilidade a intelectuais de diversos locais, etnias, religiões entre outros. É proporcionar uma diversidade cultural, um incentivo à leituras e debates fazendo parte de um conjunto de ações que podem e devem ser utilizadas nas instituições de ensino (educação infantil, ensino fundamental e médio e universidades) e nos movimentos sociais.

Os valores civilizatórios afro-brasileiros são, ainda hoje, fundamentais para uma educação antirracista, para um ambiente escolar, mas também para outros espaços, pois Azoilda nos mostra que esses valores podem ser pensados e aplicados dentro e fora do cotidiano da escola, agindo como estratégia de múltiplas atuações (SILVA, 2020:48)

Para implementarmos os valores civilizatórios afro-brasileiros nas práticas de ensino, precisamos identificar cada um e compreender como podemos utilizá-los. Esses valores que são: Memória, Ancestralidade, Religiosidade, Oralidade, Musicalidade, Cooperação/Comunitarismo, Axé (energia vital), Corporeidade, Ludicidade e Circularidade, ressaltam e valorizam a História da África e dos povos da diáspora, são princípios e normas que corporificam um conjunto de aspectos e características existenciais, espirituais, intelectuais, materiais, objetivas e subjetivas, que se construíram e se constituem num processo histórico, social e cultural, nas palavras de Azoilda:

Ao destacarmos a expressão "valores civilizatórios afro-brasileiros", temos a intenção de destacar a África, na sua diversidade, e que os africanos e africanas trazidos ou vindos para o Brasil e seus e suas descendentes brasileiras implantaram, marcaram, instituíram valores civilizatórios neste país de dimensões continentais, que é o Brasil. Valores inscritos na nossa memória, no nosso modo de ser, na nossa música, na nossa literatura, na nossa ciência, arquitetura, gastronomia, religião, na nossa pele, no nosso coração. Queremos destacar que, na perspectiva civilizatória, somos, de certa forma ou de certas formas, afrodescendentes. E, em especial, somos o segundo país do mundo em população negra (TRINDADE, 2005:30). 
Se entendemos que tudo que está neste plano terreno é sagrado, nada mais justo que tenhamos olhares e ações diferenciadas com todos os seres que vivem ao nosso redor. Essa atitude nos fará que perceber como nossa fala e nossas ações com o outro são importantes, pois:

Os valores civilizatórios afro-brasileiros forjam uma virada epistêmica na promoção de uma educação que seja efetivamente antirracista, tendo como elo a afetividade que perpassa por todo o diagrama, percebemos que estes não são de forma alguma lineares ou estáticos, mas sim, se conectam e interpenetram e se constituem num amálgama de saberes (SILVA, 2020:52).

O princípio do Axé, ou seja, a ENERGIA VITAL, está presente em tudo que é vivo e que existe, pois existe axé nas plantas, água, pedras, gente, bicho, ar, tempo, tudo é sagrado e está em interação (TRINDADE, 2005). O axé é a energia que nos move enquanto seres humanos e através desse princípio forjamos meios para nos mantermos resistentes e atuantes.

A ORALIDADE, como valor civilizatório é carregada de sentidos, marcas de nossa existência, pois a (TRINDADE, 2005) nossa fala evidencia o nosso estar no mundo, a capacidade de se comunicar e aprender com o outro. A existência dos sujeitos que foram subjugados foi marcada por silenciamentos opressores que gerou a invisibilidade de sujeitos dentro da sociedade. Portanto, o ato de falar é libertador.

A roda tem um significado muito grande para os povos da diáspora africana, pois é um valor civilizatório afro-brasileiro (TRINDADE, 2005) que resgata nossas tradições mais antigas. Através da CIRCULARIDADE podemos olhar, tocar e perceber os sentidos e sentimentos que envolvem nossas relações, pois no momento em que podemos olhar e tocar uns aos outros nos tornamos mais próximos e desenvolvemos assim uma forma diferenciada de lidar com as subjetividades do outro.

Se somos descentes de um povo que foi escravizado, pensar sobre corpo é muito importante na medida em que com ele vivemos, existimos, somos e estamos no mundo. A CORPOREIDADE (TRINDADE, 2005) compreende nosso ser e estar no mundo e, com isso, percebermos que nossas existências, subjetividades e diversidades são de suma importância. Pensar sobre corpos negros inseridos numa sociedade racista e desigual é uma tarefa diária e constante, pois estes corpos são diretamente afetados pelas mazelas sociais.

A MUSICALIDADE é um dos aspectos afro-brasileiros mais emblemáticos (TRINDADE, 2005), pois a música faz parte do nosso cotidiano e reflete muito daquilo que pensamos. A música promove momentos únicos de entrelace entre os corpos numa perspectiva de integração e harmonia, a música aguça nossos sentidos e afeta nosso estar no mundo. 
A LUDICIDADE, a alegria, o gosto pelo riso, pela diversão e celebração da vida (TRINDADE, 2005), é um dos caminhos mais fáceis para promover a interação, o senso de coletividade, a ideia de parceria. Através dos momentos de ludicidade podemos afetar o outro e descobrir formas de alegrar e celebrar. O lúdico se faz necessário a todo momento, visto que precisamos estar no mundo de forma plena e feliz.

A cultura afro-brasileira, é plural, e se baseia n coletivo e na cooperação (TRINDADE, 2005), por isso a COOPERATIVIDADE é o valor civilizatório crucial para a construção de uma sociedade que trate de forma igualitária todos sujeitos. Pensar o/no coletivo é entender que existe a possibilidade de transformar espaços e pessoas.

Nossos passos vêm de longe e, através dos valores civilizatórios afro-brasileiros surge a possibilidade de construir espaços diferenciados de ensino e convívio, pois utilizar esses valores como uma metodologia que propõe uma educação antirracista é urgente e necessário.

A diáspora africana ao fazer a travessia foi privada de trazer elementos e vínculos que pudessem compor uma MEMÓRIA para os que viriam depois, então em função disso, enquanto valor civilizatório é tão cara e importante, pois é ao sentir esses valores inscritos na nossa memória e deixar que esta aflore, cultuamos a nossa ANCESTRALIDADE, ou seja que através de nossos corpos e falas nossos ancestrais estejam presentes nas nossas ações, que possamos através de todos os valores civilizatórios afro-brasileiros, relembrar e perpetuar todas e todos que vieram antes de nós, que sempre estarão presentes nos nossos caminhos.

A RELIGIOSIDADE como valor civilizatório afro-brasileiro nos permite entender o aspecto sagrado do cuidar e ser cuidado, do ver e ser visto, do compreender e ser compreendido, do afetar e ser afetado, pois nossos corpos são como templos sagrados de uma ancestralidade potente e pujante que atua a todo momento e em todos os espaços, modificando e transformando existências.

A metodologia pensada por Azoilda demonstra que o projeto "A Cor da Cultura" parte dos valores civilizatórios afro-brasileiros para valorizar o patrimônio cultural e o reconhecimento da história do povo negro na formação da sociedade brasileira.

Os valores civilizatórios afro-brasileiros se apresentam como uma prática cotidiana de valorização da diáspora africana e nesse sentido, é uma metodologia potente e pujante forja estratégias para uma pedagogia antirracista, pois:

Nossa metodologia é polifônica e dialógica, fincada no aprenderensinaraprender. Todas as pessoas se constituem em malungas, nesta viagem/caminhada na qual o real desejo de erradicar o racismo transcendente a implementação da Lei $n^{\circ} 10.639 / 03$ e faz, de todos nós, construtores da sociedade dos nossos sonhos (BRANDÃO e SANTOS, 2015a, p. 15) 
O programa A Cor da Cultura visa pensar a escola como um local de trocas, um ambiente acessível a todos e todas de formas igualitária de qualidade e, principalmente uma formação de docentes que seja pautada numa pedagogia antirracista que seja inserida durante todo ano letivo e que seja uma metodologia da práxis, onde pense e execute ações contínuas e constantes, dito isto a metodologia do programa se baseia e três eixos fundamentais:

1) Modos de Sentir (acolhimento e diálogo), pois para que haja acolhida como aceitação do outro é necessário que haja diálogo, ou seja, a troca proporciona o acolhimento necessário do outro (de corpos e culturas);

2) Modos de Interagir (prática-teoria-prática), compreendendo que as mudanças são perceptíveis na ação cotidiana, pensar um cotidiano escolar que na prática abrace todo o corpo discente não é tarefa fácil e, por isso, implementar uma pedagogia antirracista requer um trabalho diário e contínuo;

3) Modos de Ver (valores civilizatórios afro-brasileiros): o programa "A Cor da Cultura" foi uma proposta, desde o início, para fazer pensar sobre a valorização e afirmação do patrimônio cultural africano e afro-brasileiro e teve como mote ressaltar os valores civilizatórios afro-brasileiros com o objetivo fundamentado de promover atitudes e comportamentos.

Sendo assim, a metodologia implementada no programa "A Cor da Cultura" propõe uma mudança de perspectiva nas estruturas das instituições e na ação docente, a partir de mudanças na perspectiva eurocêntrica de ensino - já que não podemos esquecer que tanto a mídia, quanto as instituições de ensino, sempre produziram conteúdos identificados com critérios e valores europeus.

\section{Considerações finais}

A representação, valorização e reconhecimento cultural da História e Cultura afrobrasileira fazem parte do processo de implementação de uma pedagogia antirracista que promove transformações na realidade da população negra do Brasil, ainda hoje vitimada pelas injustiças econômica e cultural que necessitam ser erradicadas, vale relembrar que:

Dentro desta perspectiva, a importância da educadora Azoilda Loretto da Trindade na construção de políticas afirmativas que valorizassem, dentro e fora das práticas educacionais, as relações étnico-raciais, são extremamente relevantes até hoje.

Um dos grandes legados de Azoilda foi o projeto A Cor da Cultura no qual ela foi coordenadora pedagógica (sendo seu nome indicado para o cargo tanto por militantes do movimento negro quando por profissionais da área da educação), 
que foi o grande propagador no âmbito nacional da Lei 10.639/03 para ativistas, educadoras e educadores comprometidos com uma educação antirracista (SILVA, 2020, p. 36).

As instituições de ensino são espaços de diversidade, dos encontros e das diferenças de ideias e valores e precisam, ainda hoje, de profissionais atentos a essa discussão, por estarem nas trincheiras do combate às desigualdades.

Existiu e ainda existe uma demanda por uma educação antirracista e se pensarmos que, durante um bom tempo, o programa "A Cor da Cultura" foi a grande referência para a formação de educadores e educadoras a partir da promulgação da Lei 10.639/03, então devemos ressaltar que a existência do projeto foi fundamental.

A perspectiva defendida pelo programa "A Cor da Cultura” nos mostra que é necessário implementar uma pedagogia antirracista no cotidiano escolar, estabelecendo um debate e uma luta diária contra o racismo, porém em relação às ações cotidianas o projeto foi muito bemsucedido como demonstram os seguintes dados de uma avaliação:

a) O Programa, seus desdobramentos e contribuições ${ }^{v}$

- O Programa atende, expressivamente, ao Ensino Fundamental (cerca de 70\%);

- O Programa foi expandido para outras escolas (segundo 1/3 dos gestores), por iniciativa da Secretaria, especialmente no RS e na BA;

- A Secretaria definiu políticas ou novos projetos/ações, a partir do A Cor da Cultura, segundo $54,3 \%$ dos gestores.

b) Mudanças percebidas após a implementação do Programa

- Alunos $(79 \%)$ e professores $(85,3 \%)$ estão mais sensíveis quanto à necessidade de eliminação de práticas discriminatórias;

- A maioria dos professores das escolas prioriza a discussão dos temas $(75,6 \%)$ e tem facilidade para articulá-los aos conteúdos de suas áreas e disciplinas (59,5\%).

c) Conclusões

- A avaliação foi realizada pela INNOVA Assessoria e Pesquisa entre 26/11 a 07/12/2007. Destacam-se:

- O Programa configura-se, hoje, como a iniciativa mais estruturada e sistemática em torno da valorização da cultura africana e afro-brasileira, ajudando a reduzir o "fenômeno da invisibilidade" nas escolas participantes;

- Houve aumento da sensibilidade de professores e alunos contra práticas discriminatórias; 
- O Programa começou a criar raízes em boa parte das escolas (mediante a revisão de propostas curriculares, a discussão do projeto político pedagógico ou criação de grupos de estudo em torno dos temas);

- Limites e desafios: o baixo investimento financeiro das SME; a fluidez ou inexistência de acompanhamento, pelos órgãos municipais; a participação restrita de outros atores no planejamento das ações (universidades, ONGs e outros grupos culturais e religiosos etc.).

Em função de uma memória afetiva daqueles que estiveram juntos com Azoilda neste projeto, após seu falecimento no de 2015 o programa "A Cor da Cultura" foi suspenso, mas é preciso relembrar que, durante alguns anos, foi a iniciativa mais estruturada e sistemática em torno da valorização da História e Cultura africana e afro-brasileira, ajudando a reduzir o “fenômeno da invisibilidade" e as práticas racistas nas escolas participantes.

Diante das considerações e dados apresentados, é preciso ressaltar como seria importante ter o programa em atividade novamente, incentivando a formação de educadores e educadoras das novas gerações, vislumbrando a possibilidade de atuação em todo território nacional na promoção de uma pedagogia antirracista para as instituições de ensino.

\section{Referências}

BRANDÃO, Ana Paula; SANTOS, Kátia. Saberes e Fazeres: Caderno de Textos: Projeto A Cor da Cultura. Rio de Janeiro: Fundação Roberto Marinho, 2015a.

BRANDÃO, Ana Paula; SANTOS, Kátia. Saberes e Fazeres: Caderno de Metodologial Coleção Kit Pedagógico: Projeto A Cor da Cultura. Rio de Janeiro: Fundação Roberto Marinho, 2015b.

BRASIL. Ministério da Educação. Conselho Nacional de Educação. Parecer técnico $n^{o}$ 003/2004. Brasília: Ministério da Educação, 10 de março de 2004. Disponível em: <http://portal.mec.gov.br/dmdocuments/cnecp_003.pdf〉. Acesso em 28 jul 2020.

SILVA, Gisele Rose da. Azoilda Loretto da Trindade: o baobá dos valores civilizatórios afrobrasileiros. CEFET-RJ. 163f. Dissertação (Mestrado em Relações Étnico-Raciais), Rio de Janeiro, 2020. Disponível em: <http://dippg.cefetrj.br/pprer/attachments/article/81/149_Gisele\%20Rose\%20da\%20Silva.pdf>.

TRINDADE, Azoilda Loretto da. Valores Civilizatórios Afro-brasileiros na educação.

MEC- Valores afro-brasileiros na Educação. Boletim, v. 22, 2005.

TRINDADE, Azoilda Loretto da; SANTOS, Rafael. Multiculturalismo: mil e uma faces da escola. 3. ed. Rio de Janeiro: DP\&A, 1999.

TRINDADE, Azoilda Loretto da. O racismo no cotidiano escolar. Rio de Janeiro: FGV, 1994. 249f. Dissertação (Mestrado em Educação) - Instituto de Estudos Avançados em 
Educação, Departamento de Psicologia da Educação, Fundação Getúlio Vargas, Rio de Janeiro, 1994.

\footnotetext{
${ }^{\text {i }}$ Disponível em: <http://www.acordacultura.org.br/sites/default/files/Marco\%20Conceitual.pdf>. Acesso em: 7 fev. 2020.

ii Disponível em: <http://www.acordacultura.org.br/sites/default/files/documentos/Avaliacao_do_programa_A_Cor_da_Cultura.pd f>. Acesso em: 20 abr. 2021.

iii A Cor da Cultura. Disponível em: < http://www.acordacultura.org.br/>. Acesso em: 15 jul. 2020.

iv Avaliação do programa A Cor da Cultura. Disponível em: <http://www.acordacultura.org.br/sites/default/files/documentos/Avaliacao_do_programa_A_Cor_da_Cultura.pd f>. Acesso em: 25 jul. 2020.

v Disponível em: <http://www.acordacultura.org.br/sites/default/files/documentos/Avaliacao_do_programa_A_Cor_da_Cultura.pd f>. Acesso em: 20 abr. 2021.
} 